\title{
SERUM MARKERS IN THE DIAGNOSIS OF TUBAL PREGNANCY
}

\author{
Fabio Roberto Cabar, Paula Beatriz Fettback, Pedro Paulo Pereira, Marcelo \\ Zugaib
}

doi: $10.1590 / \mathrm{S} 1807-59322008000500021$

Cabar FR, Fettback PB, Pereira PP, Zugaib M. Serum markers in the diagnosis of tubal pregnancy. Clinics. 2008;63(5): 701-8.

\begin{abstract}
The introduction of highly sensitive methods, such as transvaginal sonography and measurement of serum $\beta$-human chorionic gonadotropin, has dramatically improved ectopic pregnancy diagnosis in recent years. Early diagnosis is the key to successful and conservative management of women with ectopic pregnancy; however, approximately 50 percent of such women are initially misdiagnosed, resulting in significant morbidity and mortality. In order to improve diagnosis, several serum markers are being investigated including progesterone, CA 125, pregnancy-associated plasma protein-A, vascular endothelial growth factor, and maternal creatine kinase. Measurement of serum vascular endothelial growth factor, alone or together with other markers, could be a promising method for earlier and more accurate differential diagnosis. However, the clinical applicability of these findings remains to be evaluated in larger prospective studies.
\end{abstract}

KEYWORDS: Ectopic pregnancy; First trimester pregnancy; Progesterone; Vascular endothelial growth factor; Pregnancyassociated plasma protein A.

\section{INTRODUCTION}

Ectopic pregnancy (EP), defined as the implantation and development of the gestational sac outside of the uterine cavity, represents the fourth most frequent cause of maternal death in the United Kingdom. ${ }^{1}$

The increased incidence of EP in recent decades ${ }^{2,3}$ can be attributed to a growing number of risk factors (higher prevalence of sexually transmitted diseases, late primiparity, the use of levonorgestrel as an emergency contraceptive method, the more frequent use of assisted reproduction technologies, and increased tubal sterilization practices and subsequent attempted reversals ${ }^{4-8}$ ) and improved diagnostic methods (transvaginal ultrasound and serum measurement of the beta subunit of human chorionic gonadotrophin - $\left.\beta-\mathrm{hCG}^{4-6,9-11}\right)$.

Department of Obstetrics and Gynecology, Faculdade de Medicina da Universidade de São Paulo - São Paulo/SP, Brazil.

Tel.: 55113069.6209

Email: fabiocabar@uol.com.br

Received for publication on May 06, 2008

Accepted for publication on July, 11, 2008
Early diagnosis of first trimester hemorrhage presents an important challenge ${ }^{12}$. Transvaginal ultrasounds and serial $\beta$-hCG determinations are currently the most common methods used for diagnosis. ${ }^{12-15}$ Despite the use of high-resolution transvaginal sonography and sensitive assays for $\beta$-hCG, it is believed that 40 to $50 \%$ of cases are initially misdiagnosed. ${ }^{16}$ Transvaginal sonography has been proposed as helpful only when intrauterine gestation or an adnexal mass is observed,,${ }^{17,18}$ and serum $\beta$-hCG measurements can distinguish a normal intrauterine pregnancy (IUP) from a non-viable pregnancy, but cannot distinguish arrested IUP from EP. ${ }^{13,15,18,19}$ Ultrasound is inconclusive in up to $18 \%$ of women for whom measurement of serial $\beta$-hCG concentrations is necessary to guide management. Serum $\beta$-hCG measurement is the mainstay of rapid and early pregnancy diagnosis and is an accepted biochemical marker for successful trophoblastic implantation. ${ }^{20}$ Abnormal gestation is suspected when serial $\beta$-hCG values fall or do not rise appropriately. ${ }^{21}$ Once $\beta$-hCG is trophoblast-dependent, its serum concentration is significantly higher in women with normal IUP, but serial $\beta$-hCG determination cannot accurately separate arrested 
IUP from EP since decreased or decelerated increases in $\beta$-hCG concentrations cannot be used to discriminate between miscarriage and an EP. Consequently, $\beta$-hCG measurement is not practical when the patient presents for an emergency evaluation.

For this reason, several serum markers have been under investigation to permit earlier diagnosis of EP, and include progesterone, ${ }^{12,13,15,21-25} \mathrm{Ca}-125$, pregnancyassociated plasma protein A (PAPP-A), ${ }^{12,13,20}$ serum vascular endothelial growth factor (VEGF) ${ }^{12-15,17}$, and serum creatine kinase (CK). ${ }^{14,26,27}$

The aim of this article is to review the role of several maternal serum substances as markers of EP.

\section{PROGESTERONE}

In contrast with $\beta$-hCG concentrations, serum progesterone levels are stable for the first 8-10 weeks of gestation, ${ }^{28,29}$ and previous studies demonstrated that concentrations are higher in normal IUP. ${ }^{22-24,30}$ Consequently, serum progesterone levels may be helpful for evaluation of suspected EP if they are very high or very low. $^{21,22}$

To assess the accuracy of single serum progesterone measurement in the diagnosis of EP, a meta-analysis was performed incorporating 26 studies evaluating the performance of single serum progesterone as a diagnostic tool. ${ }^{23}$ The meta-analysis revealed that low levels of serum progesterone $(\leq 5 \mathrm{ng} / \mathrm{ml})$ could be used to correctly diagnose pregnancy failure, but that this cutoff was unable to discriminate between EP and nonviable intrauterine pregnancy. Sensitivities ranged from 44 to 100 percent, depending on the threshold. In 12 studies comprising a total of 1,107 women, only $2.6 \%$ of women with EP had progesterone levels greater than $20 \mathrm{ng} / \mathrm{ml}$; in 13 studies, only five of 1,615 women $(0.3 \%)$ with progesterone levels less than $5 \mathrm{ng} / \mathrm{ml}$ had a viable IUP. ${ }^{23}$ The authors concluded that this hormone could be used to identify women at risk for EP, but could not distinguish between EP and abnormal IUP.

Both high $(>22 \mathrm{ng} / \mathrm{ml})$ and low $(\leq 5 \mathrm{ng} / \mathrm{ml})$ cutoff points have been assessed for their ability to correctly identify nonviable and ectopic pregnancies; serum progesterone levels $\leq 5 \mathrm{ng} / \mathrm{ml}$ could apparently be used to predict EP with $70 \%$ to $90 \%$ sensitivity and $30 \%$ to $99 \%$ specificity. ${ }^{24,31}$

Serum progesterone measurements may also have prognostic efficacy when associated with serum $\beta$-hCG concentrations. Patients with progesterone levels below 10 $\mathrm{ng} / \mathrm{ml}(31.8 \mathrm{nmol} / \mathrm{L})$ and hCG levels below $1,500 \mathrm{mIU} / \mathrm{L}$ are more likely to demonstrate spontaneous resolution of EP. ${ }^{32}$
Rapid progesterone analysis can identify two important groups of women in the emergency room presenting firsttrimester vaginal bleeding/pelvic pain: those with stable pregnancy with progesterone levels $>22 \mathrm{ng} / \mathrm{ml}$ and those with levels $<5 \mathrm{ng} / \mathrm{ml}$. The first group has a high (but not definite) probability of viable intrauterine pregnancy, whereas the second almost certainly has a nonviable pregnancy. Invasive diagnostic testing (e.g. dilatation and curettage) could be postponed in the former patients, but offered to the latter, as could treatment with methotrexate (without fear of interrupting a potentially viable IUP).

\section{PAPP-A}

Normal IUP is associated with production of many placenta proteins ${ }^{13}$. Shortly after implantation, $\beta$-hCG can be found in the maternal circulation ${ }^{20}$. Trophoblastic tissue continues to synthesize and secrete various proteins throughout pregnancy, including leukemia inhibiting factor (LIF), serum specific protein-1 (SP1), human placental lactogen (HLP), and pregnancy-associated plasma protein-A (PAPP-A) . ${ }^{12,13,20}$ The biological function of these proteins is unclear, but they reflect the biosynthetic capacity of the decidualized endometrium. ${ }^{33}$

PAPP-A is synthesized by stromal cells. PAPP-A concentrations increase progressively to term, possibly as a spontaneous effect of the abundance of stromal cells. However, this substance can also found in nonpregnant persons in extrauterine sites including follicles, follicular fluid, luteal cells, and fallopian tubes. In men, this protein is present in seminal vesicles and seminal fluid. ${ }^{33}$

Previous studies demonstrated that placental protein levels are markedly reduced in EP when compared to normal IUP at the same gestational age ${ }^{13,34-36}$. Decreased circulating levels of proteins observed in EP have been proposed to reflect a smaller syncytiotrophoblastic mass. ${ }^{13}$

Sinosich et al. ${ }^{34}$ studied 116 patients, including 87 non-pregnant women, 16 patients with tubal pregnancies, and 13 women with IUP. The authors measured PAPP-A, hCG, and SP1 concentrations in 164 serum samples and 29 tissue samples obtained from these women. In the tubal pregnancy group, only two of the 47 serum samples were positive for PAPP-A. The authors indicated that clinical evidence of EP (vaginal bleeding, abdominal pain) and severely decreased or absent serum PAPP-A levels in women with a positive pregnancy test suggest a diagnosis of EP as the main possibility.

Sjöberg ${ }^{35}$ measured serum PAPP-A concentrations in 164 patients presented to gynecologic emergency services: 124 women had EP and 40 had intrauterine abortions. The PAPP-A levels in 136 women with normal IUP were 
compared with those of 460 non-pregnant women. Serum PAPP-A levels were lower in the EP and intrauterine abortion groups compared to the normal pregnancy group; they were undetectable in $82 \%$ of the EP group and 55\% of the intrauterine abortion group. Thus, the probability that a pregnant patient with undetectable PAPP-A levels has an EP was calculated to be $30 \%$; the probability of an intrauterine abortion was calculated to be $29 \%$. Although PAPP-A levels were found to be lower in individuals with ectopic pregnancies and intrauterine abortions compared to those with normal pregnancies, PAPP-A measurements cannot be used to distinguish between EP and intrauterine abortion. ${ }^{35}$ Tornehave et al. examined the tissue distribution and intensity of immunohistochemical staining for hCG, SP-1, and PAPP-A in trophoblastic and decidualized endometrial tissues of 10 women with EP. Staining was then correlated with serum concentrations of these substances. All 10 women showed strong hCG and SP-1 staining in the syncytiotrophoblast that was apparently unrelated to maternal levels of hCG and SP-1. In contrast, maternal PAPP-A levels seemed to correlate with the intensity and distribution of PAPP-A staining. Circulating PAPP-A was undetectable in 4 patients, and below the $10^{\text {th }}$ percentile in the remaining 6 . PAPP-A could not be detected in any of the decidualized endometrial tissues studied using immunohistochemical techniques. ${ }^{36}$

Recently, Daponte et al. ${ }^{12}$ evaluated whether serum concentrations of the non-placental markers VEGF, glycodelin, and progesterone and placental markers PAPP-A, HPL, and LIF differed in EP compared to abnormal IUP. A prospective study was conducted comprising 21 patients with failed pregnancy (treated by dilatation and curettage - mean gestational age 7.15 weeks) and 27 women with EP (treated by laparoscopy - mean gestational age 7.3 weeks). Serum PAPP-A, progesterone, LIF, HPL, and glycodelin levels did not significantly differ between the two groups. As a consequence, they concluded that serum concentrations of placental markers such as PAPP-A, HLP, and LIF could not be used to differentiate EP from abnormal IUP. ${ }^{12}$

\section{VEGF}

VEGF is a potent angiogenic factor that acts as a modulator of vascular growth, remodeling, and permeability in the endometrium, decidua, and trophoblast, as well as during vascular development in the embryo, all of which are crucial processes related to normal implantation and placentation. ${ }^{37}$ VEGF expression and secretion can be induced by cytokines, growth factors, hormones, and local conditions such as hypoxia. ${ }^{37,38}$ Cellular VEGF production has been shown to increase under hypoxic conditions.

The implantation environment in the oviduct is very different from that of the well-vascularized endometrium, and production and secretion of VEGF may be affected in EP. Daniel et al. first reported a difference in maternal serum VEGF levels between women with EP, abnormal IUP, and normal IUP. A prospective study comprising 20 women with EP showed that serum VEGF levels were higher in these women when compared to women with abnormal intrauterine pregnancies. A serum VEGF level > $200 \mathrm{ng} /$ $\mathrm{ml}$ was suggested for discrimination between intrauterine and extrauterine pregnancies with a specificity of $90 \%$ and PPV of $86 \%$, and between abnormal intrauterine and extrauterine pregnancies with a specificity of $80 \%$ and PPV of $86 \% .{ }^{38}$ Similarly to the previous study, Felemban et al. ${ }^{15}$ concluded that VEGF concentrations are higher in women with EP than in those with normal and arrested IUP. Fortyfive pregnant women were studied at 5 weeks of gestation, and a VEGF cut-off concentration of $200 \mathrm{pg} / \mathrm{ml}$ was found to distinguish normal intrauterine pregnancies from EP with a sensitivity, specificity, and PPV of $88 \%, 100 \%$, and $100 \%$, respectively. For discrimination of EP and abnormal intrauterine pregnancies, the sensitivity, specificity, and PPV were $87.5 \%, 75 \%$, and $77.8 \%$, respectively. ${ }^{15}$ Daponte et al. ${ }^{12}$ described higher serum VEGF concentrations in women with EP (median $227.2 \mathrm{pg} / \mathrm{ml}$ ) than in those with abnormal intrauterine pregnancy (median $107.2 \mathrm{pg} / \mathrm{ml}$ ) $(\mathrm{P}<0.001)$. The authors concluded that VEGF serum concentrations might be a useful marker for differentiating between EP and abnormal IUP, and suggested $174 \mathrm{pg} / \mathrm{ml}$ as the cut-off value for EP diagnosis. ${ }^{12}$

On the other hand, some groups have found conflicting results. Ugurlu et al. ${ }^{39}$ evaluated whether serum measurement of VEGF could be used for differentiation of EP from spontaneous miscarriages and normal intrauterine pregnancies. The study included 85 patients separated into three groups: 29 pregnant women who desired elective termination, 28 patients with previously presumed miscarriage, and 28 women with suspected EP. Serum VEGF concentrations did not show statistical differences among the women in the three groups $(\mathrm{P}=0.27)$. Therefore, the authors concluded that serum VEGF measurements should not be used to discriminate between EP and nonEP pregnancies in clinical practice. In another study, blood samples were collected from 140 women with suspected EP (pelvic pain and/or vaginal bleeding during the first trimester of pregnancy); EP diagnosis was confirmed in 62 cases. There was no difference in VEGF concentration between patients with ectopic or intrauterine pregnancies. ${ }^{40}$ Kucera-Sliutz et al. ${ }^{14}$ performed a prospective study comparing serum VEGF levels among 84 women with 
abnormal intrauterine and EP at 6 weeks of gestation (42 women in each group). They analyzed whether serum VEGF levels $>200 \mathrm{pg} / \mathrm{ml}$ could discriminate between abnormal intrauterine pregnancies and EP, and found that VEGF concentrations were not significantly different between women with abnormal intrauterine pregnancies (median, $198.5 \mathrm{pg} / \mathrm{ml}$; range, 0-701.6) and those with EP (median, $211.2 \mathrm{pg} / \mathrm{ml}$; range 0-628.8). When serum VEGF threshold concentrations $>200 \mathrm{pg} / \mathrm{ml}$ were used, abnormal intrauterine pregnancy could be distinguished from EP with a sensitivity, specificity, and PPV of $56 \%, 51 \%$, and $53 \%$, respectively. The authors concluded that VEGF could not discriminate ectopic from abnormal intrauterine pregnancies at 6 weeks of gestation, and thus should not be used for clinical management. ${ }^{14}$

In an attempt to characterize factors affecting production and secretion of VEGF in EP, expression of VEGF mRNA and the VEGF receptors KDR and flt-1 were measured in implanted and non-implanted sites of the oviduct in women with $\mathrm{EP}^{41}$. Expression was significantly higher in the implanted site in humans with EP when compared to the non-implanted site, suggesting that VEGF may play an important role in placentation and vascular development of embryos during EP.

Mueller et al performed a prospective clinical study to evaluate whether combinations of different placental and nonplacental markers could differentiate EP from normal intrauterine pregnancy. Serum values of VEGF were significantly increased in $\mathrm{EP}$, and a combination of three independent markers using the formula VEGF/ (PAPP-A x Progesterone) was found to be superior to single marker measurements for discrimination between normal intrauterine pregnancy and EP (sensitivity of 97.7\% and specificity of $92.4 \%) .{ }^{13}$

\section{CREATINE KINASE (CK)}

The lack of a submucosal layer in the fallopian tube allows the zygote to penetrate the epithelium and lay next to the muscular layer in tubal pregnancies. The trophoblast usually invades the muscle layer and maternal blood vessels are eroded, allowing muscle cell products such as CK to enter the circulation: ${ }^{26}$ therefore, increased serum CK levels are normal during EP. ${ }^{26,27}$ The pathology of arrested IUP and pelvic inflammatory disease are different, although both demonstrate no change in CK concentration. For unknown reasons, increases in $\mathrm{CK}$ are also not observed during appendicitis. Therefore, the CK assay has been proposed to be a potentially important diagnostic test for EP.

Existing evidence suggests elevated $\mathrm{CK}$ as a tool for diagnosis of ectopic pregnancy (EP). A prospective study compared serum CK levels in 90 women divided into five groups: 20 patients with tubal pregnancies, 20 patients with missed abortions, 20 age- and time of gestation-matched patients with normal pregnancies (controls), 20 patients with pelvic inflammatory disease, and 10 patients with acute appendicitis. The CK levels in women in the tubal pregnancy group were significantly higher than in the other four groups $(\mathrm{P}<0.0001)$. It was thus concluded that maternal serum CK could be an important biochemical marker in suspected tubal pregnancy. ${ }^{26}$

Saha et al. ${ }^{27}$ performed a study comprising 40 women; twenty subjects had proven EP and 20 subjects with confirmed IUP matched for gestational age were used as controls. Total serum CK levels were found to be significantly higher in the EP group as compared to the controls $(p<0.001)$, suggesting that this test might be used as a indicator for EP. ${ }^{27}$

Similarly, Katsikis et al. studied 40 women with EP; 20 with intrauterine abortive gestation and 20 normal pregnant women (controls). Total serum CK levels were measured at the time of presentation and 24 hours after surgery. Women with EP had significantly higher CK concentrations compared to women with intrauterine abortive pregnancies and controls. ROC curves demonstrated significant discriminatory capability of increased CK for EP diagnosis, suggesting that CK concentrations could be used to predict EP. $^{42}$

In contrast, recent studies have demonstrated poor sensitivity and positive predictive values for this test, suggesting that it is insufficient alone for use in clinical practice..$^{25,43,44} \mathrm{~A}$ prospective study involving 56 patients divided into 4 groups was conducted in order to assess the utility of CK measurement in the diagnosis of EP. The study enrolled 10 patients with asymptomatic tubal pregnancy, 11 patients with symptomatic tubal pregnancy, 20 patients with normal IUP, and 15 patients with threatened IUP. No significant difference was observed in the median CK values associated with normal pregnancies or threatened abortion when compared to asymptomatic or symptomatic tubal pregnancies, suggesting that serum CK is not a useful biochemical marker for EP diagnosis. ${ }^{43}$

In another study, serum CK concentrations were obtained from patients with EP prior to surgery. Controls consisted of patients with positive pregnancy tests complicated by vaginal bleeding and/or abdominal pain. There was a small, but significant difference in serum CK means between both groups $(p=0.04)$. For patients with EP, the degree of tubal distention, implantation site, and presence of tubal rupture did not affect the CK value, thereby limiting the clinical significance of this test. The authors stated that the serum CK level was statistically 
higher in EP patients than in controls, but the $\mathrm{CK}$ value distribution curve for EP was broad and overlapped with the control curve, indicating that the sensitivity and positive predictive value of this test were poor. ${ }^{44}$

\section{CA 125}

Cancer antigen 125 (CA 125) is an antigenic determinant present on a high molecular weight glycoprotein recognized by a monoclonal antibody that was raised using an ovarian cancer cell line as an immunogen. ${ }^{45}$ Serum CA 125 levels reach their highest point during the first trimester of pregnancy, between the sixth and seventh weeks, and fall to non-pregnant values during the second and third trimester. ${ }^{46}$ Elevated CA 125 levels in the maternal serum have been shown to originate from decidual cells affected by chorionic invasion or placental separation.

Although some studies indicate that serum CA 125 levels do not predict spontaneous miscarriage in the first trimester of pregnancy, ${ }^{47}$ there is inconsistent evidence regarding the use of CA 125 to distinguish between intrauterine and ectopic pregnancies.

Some authors reported that serum CA 125 levels were significantly lower in EP as compared to intrauterine pregnancies. Katsikis et al. ${ }^{48}$ investigated the predictive value of progesterone and CA 125 for the diagnosis of EP and inevitable miscarriage. Forty women with EP, 20 with intrauterine abortive gestation, and 20 normal pregnant women were studied. Women with EP had significantly lower progesterone concentrations as compared to both women with intrauterine abortive pregnancies and controls. Women with intrauterine abortions had significantly higher CA-125 levels as compared to the other two groups. It was thus concluded that measurement of progesterone and CA 125 levels were useful for discriminating ectopic and intrauterine abortive pregnancies from normal gestations. Kobayashi et al. ${ }^{49}$ measured serum CA 125 levels in 13 women with intrauterine pregnancies, nine with spontaneous abortions, three with hydatidiform moles, and 15 with EP. Serum CA 125 levels were high in patients with normal pregnancies (mean $154 \mathrm{U} / \mathrm{ml}, \pm \mathrm{SD} 169 \mathrm{U} /$ $\mathrm{ml})$, spontaneous abortions $(244 \mathrm{U} / \mathrm{ml}, \pm 258 \mathrm{U} / \mathrm{ml})$, and hydatidiform moles $(54 \mathrm{U} / \mathrm{ml}, \pm 16 \mathrm{U} / \mathrm{ml})$. In contrast, CA 125 levels were low in patients with EP $(33 \mathrm{U} / \mathrm{ml}, \pm$ $25 \mathrm{U} / \mathrm{ml})$. The difference between serum CA 125 levels in intrauterine pregnancy and EP was related to different amounts of decidual tissues at the site of trophoblastic invasion.

Sadovsky et al. ${ }^{50}$ measured serum concentrations of CA 125 in 27 women with EP and compared them with those measured in 17 women with intrauterine pregnancies; all participants were in their first trimester. The results showed that women with EP (ruptured or unruptured) were more likely to have elevated levels of serum CA 125 than women with intrauterine pregnancies.

However, some studies showed that serum CA 125 measurements failed to discriminate between spontaneous miscarriage, EP, and normal pregnancy. Schmidt et al., ${ }^{51}$ in a larger and more recent study, assessed the diagnostic value of maternal CA 125 in patients with symptomatic first trimester pregnancy. The authors followed 168 patients presenting between gestational weeks 6 and 12 comprised of 29 patients with EP, 50 patients with missed abortions, 38 patients with incomplete spontaneous abortions, 33 patients with imminent abortions, and 18 women with normal pregnancies and no history of endometriosis or ovarian mass. Patients with vaginal bleeding usually had higher median CA 125 values (38 IU/ml; range 1.3-540) than non-bleeding patients (17.8 IU/ml; range 1.0-157). No significant differences were found between median serum CA 125 levels in normal pregnancy and EP [25.5 IU/ml (range 3.2-97) and $26 \mathrm{IU} / \mathrm{ml}$ (range 1.3-157), respectively]. They concluded that single serum measurements of CA 125 in symptomatic first trimester pregnant patients failed to discriminate between spontaneous abortion, ectopic, and normal pregnancies.

Condous et al. ${ }^{52}$ evaluated the role of maternal serum CA 125 levels in predicting the outcome of pregnancies of unknown location (PUL). The final outcome of each pregnancy of unknown location was established and defined as failing PUL, intrauterine pregnancy, EP, or persisting PUL. Two hundred ninety-seven women were recruited: 153 with failing PUL (51.5\%), 116 with intrauterine pregnancies $(39.1 \%)$, and 28 with EP (9.4\%). Serum CA 125 levels were measured at 0 and $48 \mathrm{~h}$, and the values obtained at the time of presentation and change in levels after 2 days were used for the analysis. The authors concluded that routine use of serum CA 125 in the management of women with PUL is not advocated because absolute levels of maternal serum CA 125 at defined times could not be used to predict the outcome of PUL.

\section{CONCLUSIONS}

Early EP diagnosis (before rupture) permits conservative treatment, allowing for subsequent preservation of patient fertility. Investigation of new serum markers could result in earlier diagnosis, leading to timely implementation of medical treatment and prevention of tubal rupture and its complications.

In clinical practice, progesterone cannot be used as an additional diagnostic test since a single measurement 
cannot discriminate between abnormal IUP and EP. Although PAPP-A, maternal serum CK, and CA 125 concentrations were shown to be helpful for EP differential diagnosis, they do not represent methods of choice. VEGF is a promising marker for EP diagnosis. Some studies have demonstrated that VEGF measurement, as a single value or in combination with other markers, could significantly differentiate between EP and abnormal IUP during early weeks of gestation. Despite these data, the clinical applicability of VEGF measurement remains to be evaluated in larger prospective studies.

\section{REFERENCES}

1. Lewis G, Drife J. "Why Mothers Die", Triennial Report 2000-2002. The Sixth Report of the Confidential Enquiries into Maternal Deaths in the United Kingdom. London: RCOG Press, 2004.

2. Bjartling C, Osser S, Persson K. The frequency of salpingitis and ectopic pregnancy as epidemiologic markers of Chlamydia trachomatis. Acta Obstet Gynecol Scand. 2000;79:123-8.

3. Centers for Disease Control and Prevention. Ectopic Pregnancy - United States, 1990-1992. MMWR Morb Mortal Wkly Rep. 1995;44:46-8.

4. Job-Spira N, Collet P, Coste J, Brémont A, Lauman B. Risk factors for ectopic pregnancy. Results of a case-control study in the Rhone-Alpes region. Contracept Fertil Sex. 1993;21:307-12.

5. Ankum WM, Mol BW, Van der Veen F, Bossuyt PM. Risk factors for ectopic pregnancy: a meta-analysis. Fertil Steril 1996;65:1093-9.

6. Bouyer J, Coste J, Shojaei T, Pouly JL, Fernandez H, Gerbaud L, et al. Risk factors for ectopic pregnancy: a comprehensive analysis based on a large case-control, population-based study in France. Am J Epidemiol. 2003;157:185-94.

7. Pereira PP, Cabar FR, Raiza LC, Roncaglia MT, Zugaib M. Emergency contraception and ectopic pregnancy: report of 2 cases. Clinics. 2005;60:497-500.

8. Cabar FR, Pereira PP, Zugaib M. Intrauterine pregnancy after salpingectomy for tubal pregnancy due to emergency contraception: a case report. Clinics. 2007;62:641-2.
9. Chow WH, Daling JR, Cates W, Greenberg RS. Epidemiology of ectopic pregnancy. Epidemiol Rev. 1987;9:70-94.

10. Coste J, Job-Spira N, Fernandez H, Papiernik E, Spira A. Risk factors for ectopic pregnancy: a case-control study in France, with special focus on infectious factors. Am J Epidemiol. 1991;133:839-49.

11. Fernandez H, Coste J, Job-Spira N. Controlled ovarian hyperstimulation as a risk factor for ectopic pregnancy. Obstet Gynecol. 1991;78:6569.

12. Daponte A, Pournaras S, Zintzaras E, Kallitsaris A, Lialios G, Maniatis AN, et al. The value of a single combined measurement of VEGF, glycodelin, progesterone, PAPP-A, HPL and LIF for differentiating between ectopic and abnormal intrauterine pregnancy. Hum Reprod. 2005;20:3163-6.

13. Mueller MD, Raio L, Spoerri S, Ghezzi F, Dreher E, Bersinger NA. Novel placental and nonplacental serum markers in ectopic versus normal intrauterine pregnancy. Fertil Steril. 2004;81:1106-11.

14. Kucera-Sliutz E, Schiebel I, Konig F, Leodolter S, Sliutz G, Koelbl H. Vascular endothelial growth factor (VEGF) and discrimination between abnormal intrauterine and ectopic pregnancy. Hum Reprod. 2002; 17:3231-4.

15. Felemban A, Sammour A, Tulandi T. Serum vascular endothelial growth factor as a possible marker for early ectopic pregnancy. Hum Reprod. 2002;17:490-2. 
16. Abbott J, Emmans LS, Lowenstein SR. Ectopic pregnancy: ten common pitfalls in diagnosis. Am J Emerg Med. 1990; 8:515-22.

17. Cacciatore B, Stenman UH, Ylostalo P. Early screening for ectopic pregnancy in high-risk symptom-free women. Lancet. 1994;343(8896):517-8.

18. Tulandi T, Saleh A, Morris D, Jacobs HS, Payne NN, Tan SL. Effects of laparoscopic ovarian drilling on serum vascular endothelial growth factor and on insulin responses to the oral glucose tolerance test in women with polycystic ovary syndrome. Fertil Steril. 2000;74:585-8.

19. Kadar N, DeCherney AH, Romero R. Receiver operating characteristic (ROC) curve analysis of the relative efficacy of single and serial chorionic gonadotropin determinations in the early diagnosis of ectopic pregnancy. Fertil Steril.1982;37:542-7.

20. Sinosich MJ, Grudzinskas JG, Saunders DM. Placental proteins in the diagnosis and evaluation of the «elusive» early pregnancy. Obstet Gynecol Surv. 1985;40:273-82.

21. Scheid DC, Ramakrishnan K. Determining ectopic pregnancy risk using progesterone levels. Am Fam Physician 2006;73:1892.

22. McCord ML, Muram D, Buster JE, Arheart KL, Stovall TG, Carson SA. Single serum progesterone as a screen for ectopic pregnancy: exchanging specificity and sensitivity to obtain optimal test performance. Fertil Steril. 1996;66:513-6.

23. Mol BW, Lijmer JG, Ankum WM, van der Veen F, Bossuyt PM. The accuracy of single serum progesterone measurement in the diagnosis of ectopic pregnancy: a meta-analysis. Hum Reprod. 1998;13:3220-7.

24. Dart R, Ramanujam P, Dart L. Progesterone as a predictor of ectopic pregnancy when the ultrasound is indeterminate. Am J Emerg Med. 2002;20:575-9.

25. Spitzer M, Pinto AB, Dasgupta R, Benjamin F. Early diagnosis of ectopic pregnancy: can we do it accurately using a biochemical profile? J Womens Health Gend Based Med. 2000;9:537-44.

26. Chandra L, Jain A. Maternal serum creatine kinase as a biochemical marker of tubal pregnancy. Int J Gynaecol Obstet. 1995;49:21-3.

27. Saha PK, Gupta I, Ganguly NK. Evaluation of serum creatine kinase as a diagnostic marker for tubal pregnancy. Aust NZJ Obstet Gynaecol 1999;39:366-7.

28. Farquhar CM. Ectopic pregnancy. Lancet. 2005;366:583-91.

29. Stovall TG, Kellerman AL, Ling FW, Buster JE. Emergency department diagnosis of ectopic pregnancy. Ann Emerg Med. 1990;19:1098-103.

30. Perkins SL, Al-Ramahi M, Claman P. Comparison of serum progesterone as an indicator of pregnancy nonviability in spontaneously pregnant emergency room and infertility clinic patient populations. Fertil Steril. 2000;73:499-504.

31. Buckley RG, King KJ, Disney JD, Riffenburgh RH, Gorman JD, Klausen JH. Serum progesterone testing to predict ectopic pregnancy in symptomatic first-trimester patients. Ann Emerg Med. 2000;36:95100.

32. Elson J, Tailor A, Banerjee S, Salim R, Hillaby K, Jurkovic D. Expectant management of tubal ectopic pregnancy: prediction of successful outcome using decision tree analysis. Ultrasound Obstet Gynecol. 2004;23:552-6.
33. Budowick M, Johnson TR, Jr., Genadry R, Parmley TH, Woodruff JD. The histopathology of the developing tubal ectopic pregnancy. Fertil Steril. 1980;34:169-71.

34. Sinosich MJ, Ferrier A, Teisner B, Porter R, Westergaard JG, Saunders $\mathrm{DM}$, et al. Circulating and tissue concentrations of pregnancy-associated plasma protein-A (PAPP-A) in tubal ectopic gestation. Clin Reprod Fertil. 1985;3:311-7.

35. Sjoberg J. Pregnancy-associated plasma protein A in pregnancy-related gynecologic emergency. Hum Reprod. 1987;2:615-6.

36. Tornehave D, Chemnitz J, Westergaard JG, Teisner B, Poulsen HK, Bolton AE, et al. Placental proteins in peripheral blood and tissues of ectopic pregnancies. Gynecol Obstet Invest 1987;23:97-102.

37. Torry DS, Torry RJ. Angiogenesis and the expression of vascular endothelial growth factor in endometrium and placenta. Am J Reprod Immunol. 1997;37:21-9.

38. DanielY, Geva E, Lerner-Geva L, Eshed-Englender T, Gamzu R, Lessing $\mathrm{JB}$, et al. Levels of vascular endothelial growth factor are elevated in patients with ectopic pregnancy: is this a novel marker? Fertil Steril. 1999;72:1013-7.

39. Ugurlu EN, Ozaksit G, Karaer A, Zulfikaroglu E, Atalay A, Ugur M. The value of vascular endothelial growth factor, pregnancy-associated plasma protein-A, and progesterone for early differentiation of ectopic pregnancies, normal intrauterine pregnancies, and spontaneous miscarriages. Fertil Steril. 2008 Apr 8. [Epub ahead of print].

40. Gerton GL, Fan XJ, Chittams J, Sammel M, Hummel A, Strauss JF, Barnhart K. A serum proteomics approach to the diagnosis of ectopic pregnancy. Ann N Y Acad Sci. 2004;1022:306-16.

41. Lam PM, Briton-Jones C, Cheung CK, Leung SW, Cheung LP, Haines C. Increased messenger RNA expression of vascular endothelial growth factor and its receptors in the implantation site of the human oviduct with ectopic gestation. Fertil Steril. 2004;82:686-90.

42. Katsikis I, Rousso D, Farmakiotis D, Kourtis A, Diamanti-Kandarakis E, Zournatzi-Koiou V, et al. Creatine phosphokinase in ectopic pregnancy revisited: significant diagnostic value of its $\mathrm{MB}$ and MM isoenzyme fractions. Am J Obstet Gynecol. 2006;194:86-91.

43. Vitoratos N, Gregoriou O, Papadias C, Konidaris S, Kalogirou D, Kalampokis D, et al. Clinical value of creatinine kinase in the diagnosis of ectopic pregnancy. Gynecol Obstet Invest. 1998;46:80-3.

44. Kurzel RB, Mazdisnian F, Paige S, Liu P. Serum creatine kinase is not a reliable indicator of ectopic pregnancy. Int J Fertil Womens Med. 2001;46:300-3.

45. Jacobs I, Bast RC Jr. The CA 125 tumour-associated antigen: a review of the literature. Hum Reprod. 1989;4:1-12.

46. Check JH, Vetter BH. A challenge to the concept of tubal reflux to explain the rise and fall of CA125 in serum during the first trimester. Hum Reprod. 1995;10:674-6.

47. Hornstein MD, Check JH, Hill JA. Serum CA 125 levels and spontaneous abortion. Am J Obstet Gynecol. 1995;172:695-9.

48. Katsikis I, Rousso D, Farmakiotis D, Kourtis A, Diamanti-Kandarakis E, Panidis D. Receiver operator characteristics and diagnostic value of progesterone and CA-125 in the prediction of ectopic and abortive intrauterine gestations. Eur J Obstet Gynecol Reprod Biol. $2006 ; 125: 226-32$ 
49. Kobayashi F, Takashima E, Sagawa N, Mori T, Fujii S. Maternal serum CA125 levels in early intrauterine and tubal pregnancies. Arch Gynecol Obstet. 1993;252:185-9.

50. Sadovsky Y, Pineda J, Collins JL. Serum CA-125 levels in women with ectopic and intrauterine pregnancies. J Reprod Med. 1991;36:875-8.

51. Schmidt T, Rein DT, Foth D, Eibach HW, Kurbacher CM, Mallmann P, et al.
52. Prognostic value of repeated serum CA 125 measurements in first trimester pregnancy. Eur J Obstet Gynecol Reprod Biol. 2001;97:16873 .

53. Condous G, Kirk E, Syed A, Van Calster B, Van Huffel S, Timmerman $\mathrm{D}$, et al. Do levels of serum cancer antigen 125 and creatine kinase predict the outcome in pregnancies of unknown location? Hum Reprod. 2005;20:3348-54. 